\title{
Effect of Powder Form and SPS Process Sintering on CuCr50 Alloy Powder
}

\author{
Xian Zhai \\ Wuhan University \\ School of Mechanical and Power \\ Engineering \\ Wuhan,China \\ zhaixian123@163.com \\ Wenkai Xiao \\ Wuhan University \\ School of Mechanical and Power \\ Engineering \\ Wuhan,China \\ xiaowenkai@whu.edu.cn
}

\author{
Kunqi Mudi \\ Wuhan University \\ School of Mechanical and Power \\ Engineering \\ Wuhan, China \\ 1485299523@qq.com \\ Xuefeng Ruan \\ Wuhan University \\ School of Mechanical and Power \\ Engineering \\ Wuhan, China \\ 2532564342@qq.com
}

switch apparatus aiming to high voltage and large power, contact material is required to have a higher conductivity and mechanical properties. Therefore, $\mathrm{CuCr}$ alloy is widespread adoption in the electrical contact materials when it comes to manufacturing high power vacuum circuit breakers, and it plays a decisive role in the switching performance.[2-4]

At present, the melt infiltration method and the mixed powder sintering process are mainly adopted as traditional manufacturing process in production of $\mathrm{CuCr}$ contact materials. Contact materials manufactured by the melt infiltration method has better mechanical strength, but they are easy to form macro porosity and composition segregation. Contact materials manufactured by the mixed powder sintering process has a uniform metallographic structure, low mechanical strength, and they are difficult to realize densification[5-6]. In this paper,we adopt MA to activate $\mathrm{CuCr} 50$ alloy powder so that the powder can be mixed uniformly. Then, we make a research into the microstructure of $\mathrm{CuCr}$ alloy powder. And then we Sintering $\mathrm{CuCr} 50$ alloy powder by SPS. It effectively resolves the problems above. At the same time, it greatly improves the comprehensive performance of the contact materials.

\section{MATERIALS and METHODS}

Keywords: spark plasma sintering;electrical
conductivity;hardness;scanning electron microscope morphology;microstructure and properties

\section{INTRODUCTION}

In the $\mathrm{CuCr}$ alloy, one component $\mathrm{Cu}$ has lower melting point, higher conductivity and better plasticity than $\mathrm{Cr}$. The other component $\mathrm{Cr}$ has higher melting point, higher mechanical strength and lower chopping current than $\mathrm{Cu}$. The solubility of $\mathrm{Cr}$ in $\mathrm{Cu}$ is low so that $\mathrm{CuCr}$ alloy material has a superior performance, such as high breaking current capacity, high voltage withstanding stress and less burnt loss. At present, with the development of
Operation of MA is in the machine the QM-1SP2-CL planetary ball mill,at the speed of $250 \mathrm{r} / \mathrm{min}$ for 5.5 hour. The grain size of the the original $\mathrm{Cu}$ powder and $\mathrm{Cr}$ powder used in the experiment is nearly 300\#(300 mesh) and 200\#(200mesh) respectively. The powder mixture put in the stainless steel ball-milling jar comprises $\mathrm{Cu}$ powder and $\mathrm{Cr}$ powder in the mass percent of $1: 1$. The milling media consists of acemented carbide balls. Evacuate the ball-milling jar to $-0.1 \mathrm{~Pa}$ before ball-milling, then dry the milled MA powder for 3 hour under vacuum after the ball milling. The quality of added graphite powder and carbon nanotubes powder is $1 \%$,mixing in the 
grinding device.And Then sintering the dried MA powder in the SPS320MK II under the heating rate of $100^{\circ} \mathrm{C} / \mathrm{min}$ with $50 \mathrm{Mpa}$ pressure and $900^{\circ} \mathrm{C}$, thermal insulating for 5 minute. View the microtopography of the powder sample under the scanning electron microscope whose type is QUANTA200. Measure electrical conductivity with the SB2230 Digital direct current resistance measuring instrument. Measure the hardness with the HVA -10 vickers hardness tester.Test density by drainage method.

\section{EXPERIMENTAL RESULTS and ANALYSIS}

\section{A. SEM Analysis of Metal Powder}

The original powder morphology is shown in Figure 1a, b, c, d. 1a is $200 \#$ electrolytic copper powder,whose morphology is the pine needle. $1 \mathrm{~b}$ is $300 \#$ electrolytic copper powder; 1c is 200\# electrolytic copper powder, whose morphology is flake. $1 \mathrm{~d}$ is $200 \#$ electrolytic $\mathrm{Cr}$ powder,whose morphology is irregular granular.
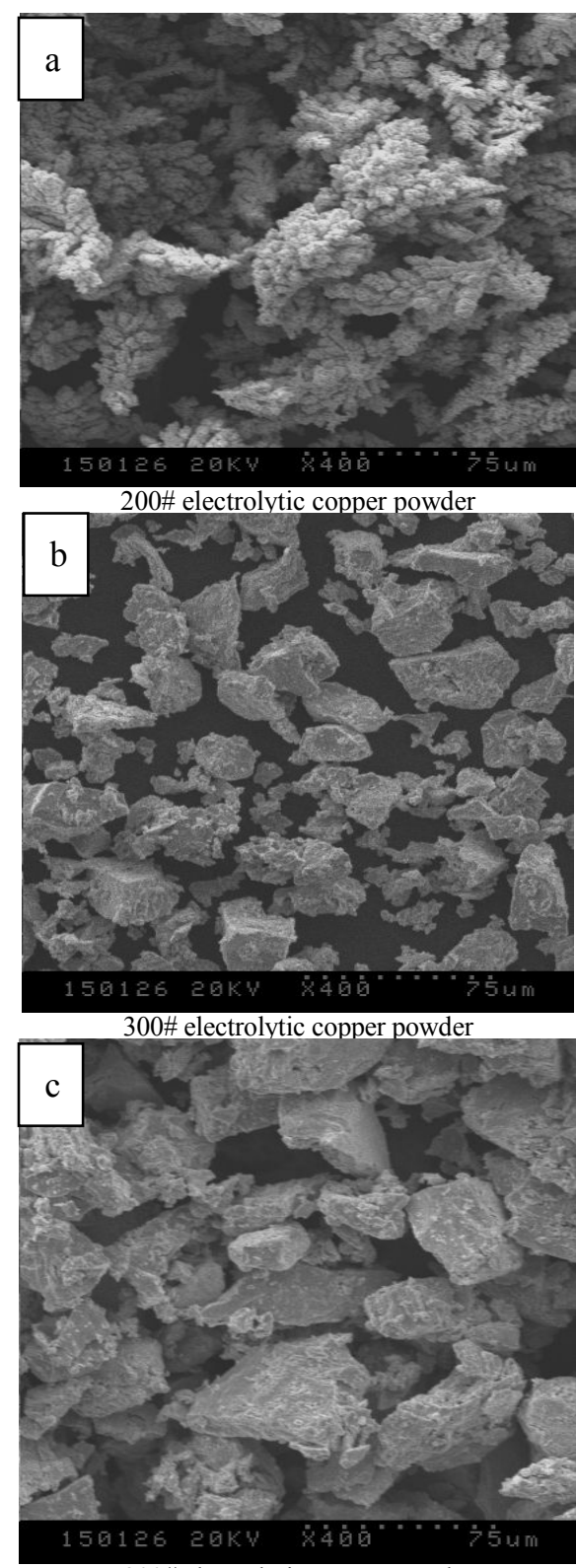

200\# electrolytic copper powder

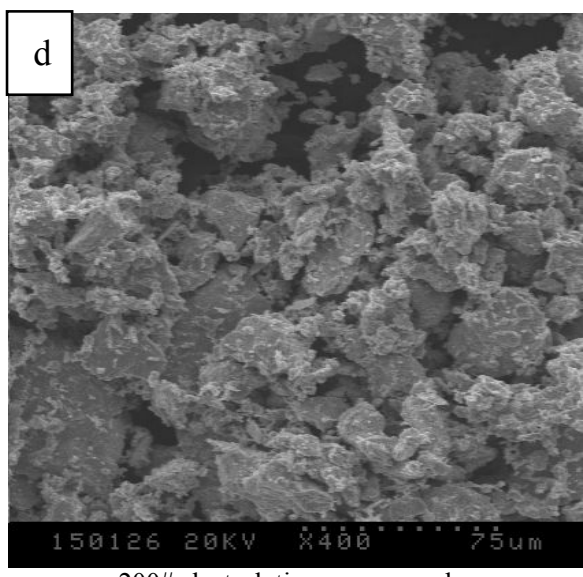

200\# electrolytic copper powder

Figure 1. SEM micrographs milled $\mathrm{Cu}$ powder and $\mathrm{Cr}$ powder
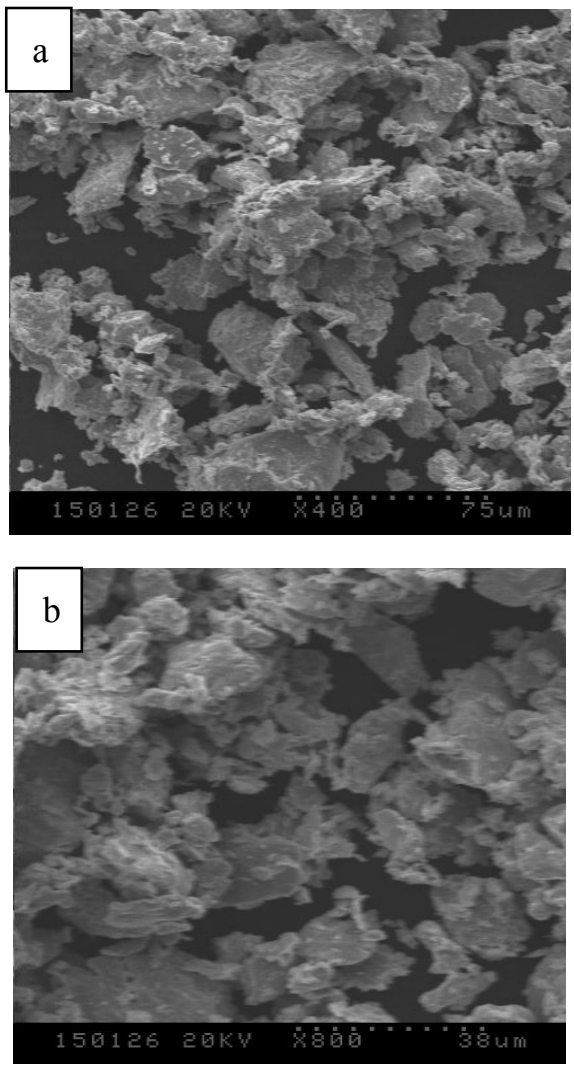

Figure 2. SEM micrographs milled $\mathrm{Cu}$ powder and $\mathrm{Cr}$ powder for MA 5.5 hour

After dealing with MA process, powder particle morphology is shown in the Figure 2. $2 \mathrm{a}$ is the alloy powders include $300 \#$ flake $\mathrm{Cu}$ powder and $200 \# \mathrm{Cr}$ powder afer MA. During the MA, alloy powder occurs frequent collision among ball mill medium, ball mill and medium tank wall, which leads to work hardening and the circulation of the rupture process.[7] Since $\mathrm{Cu}$ powder has a good plasticity and ductility and $\mathrm{Cr}$ powder has a large brittleness, $\mathrm{Cr}$ powder's fracture and broken is more significant than $\mathrm{Cu}$ powder during the process of MA. Which lead to the final powder particle size refined than the original size of $\mathrm{Cr}$ powder. As is shown in the Figure $2,2 \mathrm{a}$ and $2 \mathrm{~b}$ reflects that the mixed powder formed flake $\mathrm{Cu}$ and $\mathrm{Cr}$ composite particles. That is to say,alloy powder mixed uniformity. 


\section{B. Metallographic Structure}
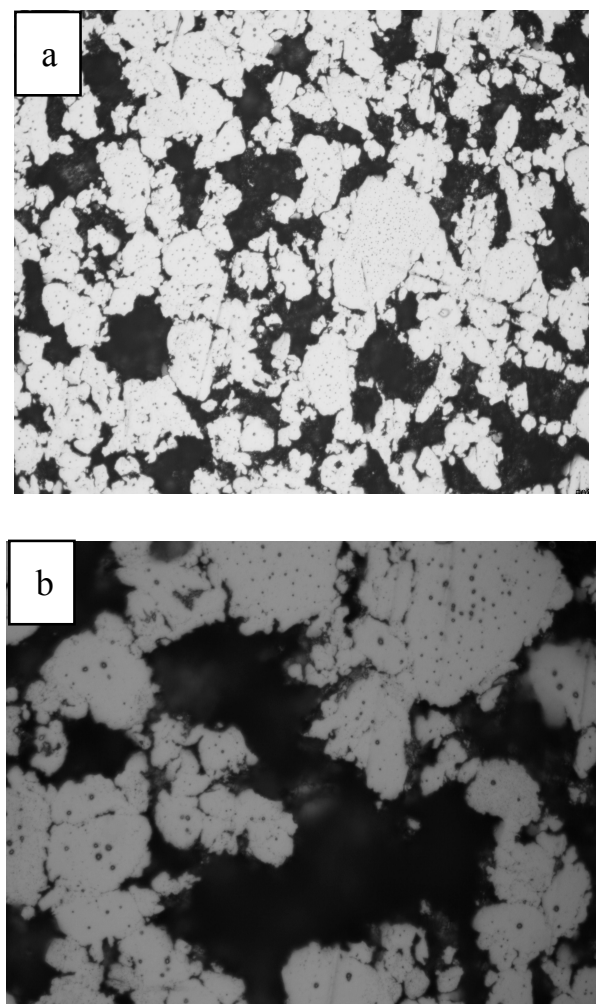

Figure 3. metallographic structure of $\mathrm{CuCr} 50$ alloy in different magnification

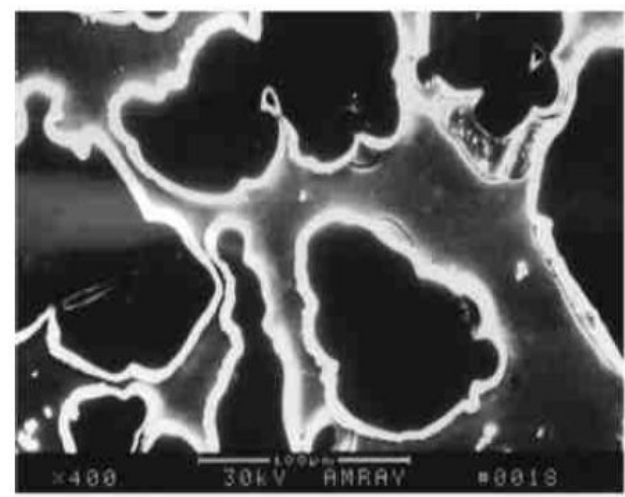

Fig .4 SEM of CuCr50

As is shown in the figure $3,3 \mathrm{a}$ is the metallographic in 200 times magnification, $3 \mathrm{~b}$ is the the metallographic in 500 times magnification the white structure is $\mathrm{Cu}$ and the black structure is Cr. In the Fig. 4[8], the continuous phase is the $\mathrm{Cu}$ phase and the isolated phase is the $\mathrm{Cr}$ phase. $\mathrm{Cr}$ phase is the precipitate on the $\mathrm{Cu}$ matrix. $\mathrm{Cr}$ is random distribution in irregular block on $\mathrm{Cu}$ the substrates.[9] $\mathrm{Cu}$ and $\mathrm{Cr}$ present uniform mixing.

As is shown in the figure 5,5a is the metallographic in 200 times magnification added graphite powder, $5 \mathrm{~b}$ is the the metallographic in 500 times magnification added graphite powder.In the figure $6,6 \mathrm{a}$ is the metallographic in 200 times magnification added carbon nanotube graphite powder, $6 \mathrm{~b}$ is the the metallographic in 500 times magnification added carbon nanotube graphite powder.the white structure is $\mathrm{Cu}$ and the black structure is $\mathrm{Cr}$. $\mathrm{Cr}$ phase is the precipitate on the $\mathrm{Cu}$ matrix. $\mathrm{Cu}$ and $\mathrm{Cr}$ present uniform mixing. The appearance of graphite and carbon nanotubes is not obvious under the metallurgical microscope.
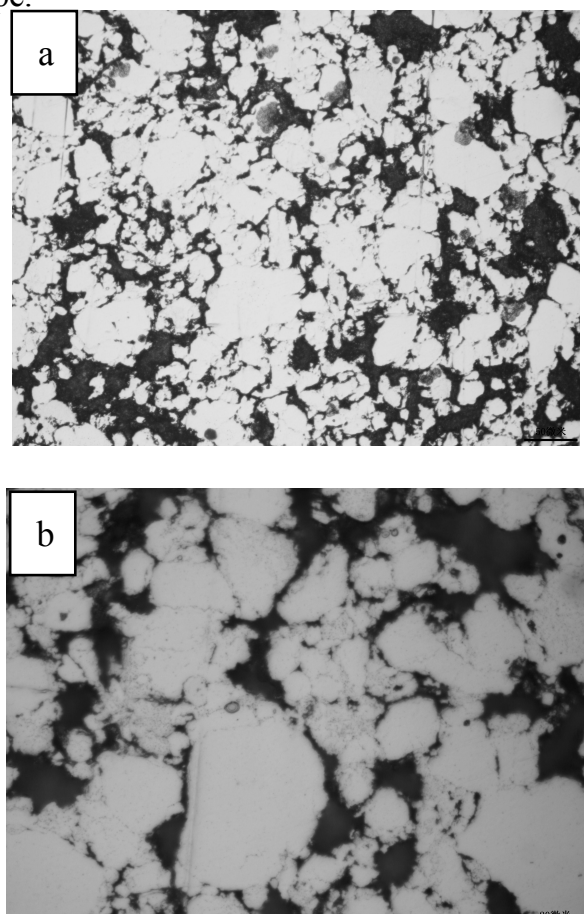

Figure 5. metallographic structure of $\mathrm{CuCr} 50$ alloy added graphite powder in different magnification
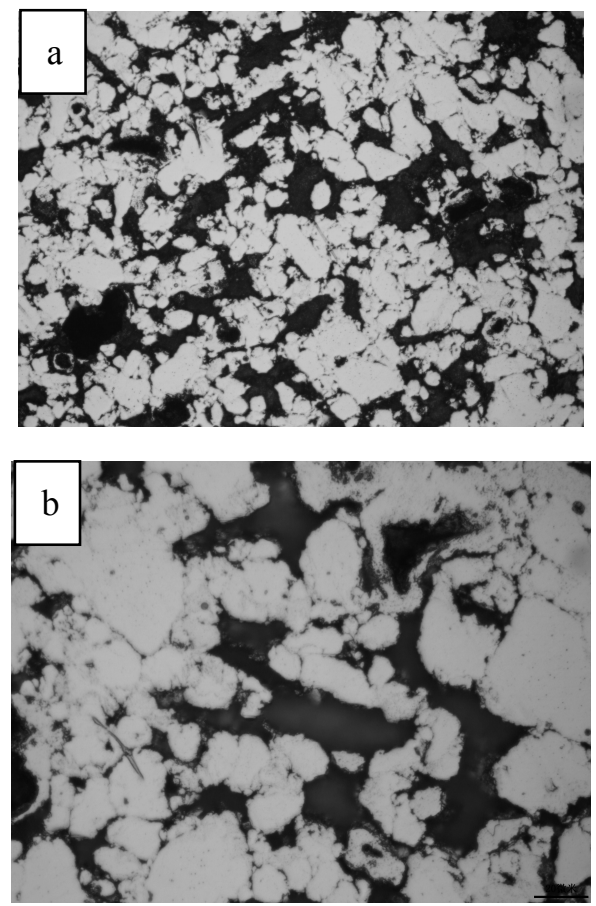

Figure 6. metallographic structure of $\mathrm{CuCr} 50$ alloy added carbon nanotube powder in different magnification

\section{Conductivity and Micro-Hardness Analysis}

We named the mixture of pine needle $\mathrm{Cu}$ powder and $\mathrm{Cr}$ powder $\mathrm{NO} .1$, the mixture of $300 \#$ flake $\mathrm{Cu}$ powder and $\mathrm{Cr}$ powder $\mathrm{NO} .2$, and the mixture of $200 \#$ flake $\mathrm{Cu}$ powder and Cr powder NO.3and the mixture of 300\# flake $\mathrm{Cu}$ powder and $\mathrm{Cr}$ powder added graphite powder 
NO.4,and the mixture of $300 \#$ flake $\mathrm{Cu}$ powder and $\mathrm{Cr}$ powder added carbon nanotube graphite powder NO.5.Their conductivity and hardness result in the Table 1 and Table 2.

TABLE 1. CONDUCTIVITY AND HARDNESS FOR EACH SAMPLE

\begin{tabular}{|c|c|c|c|}
\hline NO. & 1 & 2 & 3 \\
\hline $\begin{array}{c}\text { Conductivity } \\
\text { (Ms/m) }\end{array}$ & 9.70 & 12.12 & 12.87 \\
\hline $\begin{array}{c}\text { Electrical } \\
\text { conductivity } \\
\text { increase } \\
\text { (Relative to } \\
\text { No.1) }\end{array}$ & 0 & $24.9 \%$ & $32.7 \%$ \\
\hline $\begin{array}{c}\text { Microhardness } \\
\text { (HV) }\end{array}$ & 299.3 & 268.5 & 254.6 \\
\hline Relative density & $98.02 \%$ & $98.27 \%$ & $98.10 \%$ \\
\hline
\end{tabular}

After dealing with MA process, the $\mathrm{Cu}$ atom and $\mathrm{Cr}$ atom is fine and homogeneous mixing, which makes it possible to produce the $\mathrm{CuCr} 50$ with balance organization and fine grains for lower temperature and shorter time. As is shown in the Table 1,after sintering of SPS by 5 minute and $900^{\circ} \mathrm{C}$, it can be seen that the flake $\mathrm{Cu}$ powder can get an increasing by $24.9 \%$ comparing to the pine needle $\mathrm{Cu}$ powder, and the larger flake ones can get an increasing by $32.7 \%$. With the mixing of $\mathrm{Cr}$ powder, the strength and the hardness of the material is enhanced. Cr Separates out with tiny dot uniform dispersion in the $\mathrm{Cu}$ substrate.[10]According to the microtopography of $\mathrm{Cu}$, the flake ones are softer than the pine needle ones and the larger size flake ones are softer than the smaller ones when they are mixed in the material.

TABLE 2. CONDUCTIVITY AND HARDNESS FOR ADDED GRAPHITE POWDER AND ADDED CARBON NANOTUBE POWDER

\begin{tabular}{|c|c|c|c|}
\hline NO. & 2 & 4 & 5 \\
\hline $\begin{array}{c}\text { Conductivity } \\
\text { (Ms/m) }\end{array}$ & 12.12 & 10.87 & 12.7 \\
\hline $\begin{array}{c}\text { Electrical } \\
\text { conductivity } \\
\text { increase } \\
\text { (Relative to No.2) }\end{array}$ & $24.9 \%$ & $-10.16 \%$ & $4.96 \%$ \\
\hline $\begin{array}{c}\text { Microhardness } \\
\text { (HV) }\end{array}$ & 268.5 & 354.2 & 346.6 \\
\hline Relative density & $98.27 \%$ & $98.20 \%$ & $98.26 \%$ \\
\hline
\end{tabular}

As is shown in the Table 2, after adding graphite powder or carbon nanotube graphite powder,relative density is almost no changes, and the hardness rises with the adding of graphite powder or carbon nanotube graphite powder.while the electrical conductivity improves slightly, the electrical conductivity even gets declined due to the blocking effect of graphite powder.

\section{CONCLUSIONS}

(1)The powder of $\mathrm{Cu}$ and $\mathrm{Cr}$ turn into supersaturated solid solution after $5.5 \mathrm{~h}$ mechanical alloying, forming the flake $\mathrm{Cu}$ powder and $\mathrm{Cr}$ composite particles which are mixing uniformity.

(2)The CuCr50 lump which has fine particles and mixing uniformity powder can be produced by SPS with the parameter of $900{ }^{\circ} \mathrm{C}, 5 \mathrm{mins}$, and the lump has higher conductivity and harder hardness.

(3)The morphology of the $\mathrm{Cu}$ powder is related to the conductivity and hardness of the $\mathrm{CuCr} 50$. The flake ones are better than the pine needle ones and the larger the flake powders are, the lower conductivity and harder hardness can be obtained.

(4)After adding graphite powder or carbon nanotubes powder into the flake $\mathrm{Cu}$ powder, the effect of improving the conductivity of $\mathrm{CuCr} 50$ alloy is not obvious. Graphite powder can reduce electrical conductivity, and carbon nanotubes powder improve the electrical conductivity slightly.

\section{REFERENCES}

[1] Chengdong Xia, Baohong Tian,"Current Research Status on $\mathrm{CuCr}$ Alloy for Contact Material”, fournday technology,Vol. 28 No.1 Jan. 2007,pp.139-141.

[2] Slade P G. "Advances in materials development for high power vacuum int errupter contacts", IEEE.Trans on CPMT, $1994,17(1): 96$.

[3] Werner F R, Michael S, Glatzle W et al .IEEF Trans on CHMT, $1989,12(2): 273$.

[4] Morris M A., Morris D G .Acta Metall, 1987, 35(10):2511

[5] Shiqiang Lu,Chunwen Hu."Mechanical activation preparation $\mathrm{CuCr} 50$ contactor material microstructure and properties of hot pressing". Rare metal materials and engineering. 2007,6(36):1041.

[6] Yongan Zhang,Baiqing Xiong."CuCr50 alloy powder preparation and microstructure analysis." Chinese journal of rare metals.2002,7 (26) : 245

[7] Zhu Yongbing,Shen Yifu, "Fabrication of W-Cu Nano-Crystalline Composite Precursor Powders by Mechanical Alloying". Rare metal materials and engineering.2007 Vol.36 No.6 P.1091-1094.

[8] Liang Shuhua, Fan Zhikang, Hu Rui."investigation on the Optimum Heat $\mathrm{T}$ reatment Process of $\mathrm{CuCr} 50$ Contact Materials"transactions of metal heat treament.Vol .21 No .3 September 2000.pp.66-68.

[9] Chang limin,Xiao Ying,Hao Wenguang,"effect of deformation and heat treament on morphology of Phase and Properties of $\mathrm{CuCr}$ alloy",rare metal materials and engineering.vol.34,No.1,December 2005.pp.1952-1954.

[10] Liang Shuhua,Fang Zhikan. "technology of powder metallurgy".transactions of metal heat treament.Vol.18 No .3 September 2000.pp.196-198.d 